\title{
Spillovers between Bitcoin and other Assets during Bear and Bull Markets
}

\section{Elie Bouri}

USEK Business School, Holy Spirit University of Kaslik (USEK), P.O. Box 446, Jounieh, Lebanon. E-mail: eliebouri@ usek.edu.lb

\section{Mahamitra Das}

Economic Research Unit, Indian Statistical Institute, Kolkata, 203 B.T. Road, Kolkata-108, India. E-mail: mahamitra0787@gmail.com

\author{
Rangan Gupta \\ Department of Economics, University of Pretoria, Pretoria, 0002, South Africa. \\ Email: rangan.gupta@up.ac.za
}

\section{David Roubaud}

Montpellier Research in Management, Montpellier Business School

2300 Avenue des Moulins, 34080 Montpellier, France. E-mail: d.roubaud@ @ontpellier-bs.com

\begin{abstract}
This paper contributes to the embryonic literature on the relations between Bitcoin and conventional investments by studying return and volatility spillovers between this largest cryptocurrency and four asset classes (equities, stocks, commodities, currencies, and bonds) in bear and bull market conditions. We conducted empirical analyses based on a smooth transition VAR GARCH-in-mean model covering daily data from July 19, 2010 to October 31, 2017. We found significant evidence that Bitcoin returns are related quite closely to those of most of the other assets studies, particularly commodities, and therefore, the Bitcoin market is not isolated completely. The significance and sign of the spillovers exhibited some differences in the two market conditions and in the direction of the spillovers, with greater evidence that Bitcoin receives more volatility than it transmits. Our findings have implications for investors and fund managers who are considering Bitcoin as part of their investment strategies and for policymakers concerned about the vulnerability that Bitcoin represents to the stability of the global financial system.
\end{abstract}


Keywords: Bitcoin; asset classes; return and volatility spillovers; asymmetry; smooth transition; bivariate GARCH-M.

\section{JEL Classification: C11; G15.}

\section{Introduction}

Intermarket links, as measured by return and volatility spillovers, represent an important aspect of international finance and have crucial implications for portfolio and hedging decisions. This topic has received considerable attention in the empirical literature, with evidence of increased market integration driven by openness of markets, globalization, financialization, and technological developments.

With the emergence of Bitcoin as the first and most popular cryptocurrency, attention shifted in part to this new asset, especially in 2016 and 2017, during which it became highly prominent in the investment scene and financial press. Bitcoin prices increased by more than $1358 \%$ in 2017 alone, giving it a total market value in excess of 215 billion USD. Importantly, Bitcoin joined the club of legitimate assets when the Chicago Mercantile Exchange (CME) Group and the Chicago Board Options Exchange's (CBOE) launched future contracts based on the price of Bitcoin in December 2017. Many market participants perceive this move as the legitimatization of Bitcoin as an investment asset. It follows that there is a need to investigate and determine the return and volatility associations between Bitcoin and other asset classes for the sake of investors and policymakers. This is important to our case, given that Bitcoin is characterized by extremely high levels of return and volatility (Baek and Elbeck, 2015) that could affect other asset classes and thereby the stability of the financial system (European Central Bank, 2012). Any evidence of significant return and volatility spillovers between Bitcoin and other asset classes potentially affects not only asset selection and allocation, and risk management decisions, but also regulators' policies designed to maintain the stability of the global financial system. It also is important to policymakers who are considering Bitcoin as part of their foreign reserves or experimenting with the own versions of cryptocurrency.

Thus far, the few studies that have explored the relation between Bitcoin and financial variables have addressed only a few assets at a time, such as UK equities, EUR/USD, GBP/USD (Dyhrberg, 2016), alternative monetary systems (Rogojanu and Badea, 2014), metals and 
currencies (Baur et al., 2015), global macro-financial development (Ciaian et al., 2016), energy and non-energy commodities (Bouri et al., 2017b), and global uncertainty (Bouri et al., 2017a). Importantly, the existing literature lacks empirical studies on the return and volatility spillovers between Bitcoin and other asset classes and the potential difference in the spillovers between bull and bear market conditions. This study attempted to address these gaps. Specifically, the main contributions of this study highlighted several aspects. First, we considered a rich set of four asset classes (equities, bonds, currencies, and commodities), in which we employed three proxies of equity markets: world, emerging markets, and Chinese equity indices. We opted for emerging markets because of Bitcoin's rising popularity in these countries. We also focused particularly on China, as Bitcoin is used there to overcome capital control. We considered bonds, US dollars, gold, and the general commodity index because of scholars lack of consensus whether Bitcoin, which is independent of central authorities, is a currency, digital gold, commodity, or synthetic commodity (Selgin, 2015). We also included crude oil and energy prices in the analysis, given empirical evidence that Bitcoin mining consumes considerable oil and energy ${ }^{1}$ (Hayes, 2016). Second, we used a bivariate model that has the advantages of incorporating several important specifications, such as smooth transition, asymmetry, and dynamic conditional correlations (e.g., see Kundu and Sarkar, 2016; Chowdhury et al., 2018). Accounting for asymmetry and smooth transition behavior to switch between bull and bear markets was expected to add value to the existing literature on intermarket associations between Bitcoin and other asset classes, which has been dominated to date by the use of conventional and univariate models. These techniques do not account for nonlinearity and asymmetry and fail to differentiate between bull and bear markets. Third, we accounted for the presence of structural breaks that most often alter the reliability of the spillover effects.

The remainder of the paper is structured as follows: Section 2 reviews the literature on Bitcoin and its relation with certain other conventional assets. Section 3 describes the methods. Section 4 presents the data and discusses the empirical results, and Section 5 provides conclusions.

1 In a recent press release, Morgan Stanley indicated that the mining of Bitcoin and other cryptocurrencies could require approximately 140 terra watt-hours of electricity in 2018. 


\section{Literature review}

Bitcoin was launched as a global solution to the distrust and uncertainty in the financial landscape. Accordingly, it often is considered an aspect of an alternative 'peer-to-peer' economy (Bouri et al., 2017b), which makes it useful as an alternative investment during economic and financial crises ${ }^{2}$. However, the literature disagrees on whether Bitcoin fulfils the criteria of a currency or commodity. Yermack (2013) rejected the claim that Bitcoin is money, Polasik et al. (2015) view it as a medium of exchange, and Selgin (2015) considers it a synthetic commodity money.

Many studies have addressed the legal, ethical, and technological aspects of Bitcoin and some recent studies have considered its economic and financial aspects. Kriftousek (2015) used a wavelet method and found that the Chinese market index seems to be a main determinant of Bitcoin prices, while the price of gold plays a marginal role. Bouoiyour and Selmi (2015), who used a cointegration approach, reported quite similar results. Bauret et al. (2015) showed that Bitcoin is useful as a diversifier because of its very weak correlation with bonds and equities. Brière et al. (2015) studied the correlation between Bitcoin and several conventional assets (worldwide equity indices, bonds, fiat currencies) and unconventional assets (commodities, hedge funds, real estate), and demonstrated that, although Bitcoin exhibits high levels of volatility, the risk-return trade-off of well-diversified portfolios can be enhanced by allocating $3 \%$ to Bitcoin investment. Ji et al. (2017) used a directed acyclic graph approach and revealed that Bitcoin is useful in diversification because of its isolation from conventional assets. However, these foregoing studies relied on unconditional correlation analysis and did not account for return and volatility spillovers, particularly under different market conditions. Dyhrberg (2016) relied on univariate GARCH models and indicated Bitcoin's ability to hedge against movements in UK currency and equities. However, multivariate GARCH models often have been found to reveal more about links across markets. Using regression models augmented with dummy variables, Bouri et al. (2017b) confirmed some of Baur et al. (2015) and Brière et al.'s (2015) findings. Specifically, they revealed that Bitcoin is indeed an effective diversifier against movements in energy commodities. However, the authors did not consider return and volatility associations under different market conditions and overlooked nonlinearity and

${ }^{2}$ For example, Luther and Salter (2017) indicated that the interest in Bitcoin increased considerably following the bailout deal between Cyprus and international lenders. 
asymmetric aspects. Bouri et al. (2017a) applied a wavelet-based approach, and indicated that bitcoin is a hedge against global uncertainty, as measured by the implied volatility indices of developed and emerging markets. Balcilar et al. (2017) provided evidence of the nonlinear effect of trading volume on Bitcoin's returns and volatility while differentiating between bull and bear market conditions. However, there is little empirical evidence of the return and volatility spillovers between Bitcoin and other asset classes and the potential differences in the spillovers between bear and bull markets. Thus, this is where we seek to contribute. Given the unique factors that affect Bitcoin returns, such as their attractiveness (Ciaian et al., 2016; Kristoufek, 2013), anonymity of payment transactions (EBA, 2014; Yermack, 2013), used in illegal activities and on the part of computer programming enthusiasts (Yelowitz and Wilson, 2015), cyberattacks (Moore and Christin 2013), and cost of mining (Hayes, 2016; Li and Wang, 2016), it often is argued that the Bitcoin market is related very weakly to other global macroeconomic aggregates (Brière et al., 2015; Polasik et al., 2015) and to most conventional asset classes (Baur et al., 2015; Brière et al., 2015; Dyhrberg, 2016; Bouri et al., 2017b).

\section{Methodology}

In this section, we present the methodological framework that we used to examine return and volatility spillovers between Bitcoin and several asset classes in bull and bear markets. We applied a bivariate GARCH-in-mean (BTGARCH-M) model with a Dynamic Conditional Correlation (DCC) approach to model volatility, and the smooth transition vector autoregressive (STVAR) specification. Specifically, this STVAR-BTGARCH-M model switches from one market condition to another and permits an asymmetry in conditional variance according to market situations. The 'in-mean' component in the model captures explicitly the effects of different volatility spillovers on returns. Different hypotheses of asymmetric spillovers of returns and volatility were formulated and then tested using the Wald test.

We present the basic framework of the model below, and then describe the standard multivariate GARCH model with constant and DCC representation. Thereafter, we describe the specification of our model and the subsequent formulation of asymmetric spillovers hypotheses. 


\subsection{Basic framework of the model}

The basic framework of the model applied in this paper is:

$r_{t}=\mu_{t}(\theta)+\varepsilon_{t}$

where $r_{t}$ is an $N \times 1$ vector of returns at time $t$ on $N$ equity indices within a country, $\mu_{t}(\theta)$ is the $N \times 1$ conditional mean vector that also includes the 'in-mean' component, $\varepsilon_{t}=H_{t}^{1 / 2}(\theta) \eta_{t}$, with $E\left(\eta_{t}\right)=0$ and $V\left(\eta_{t}\right)=I_{N}, I_{N}$ is the identity matrix of order $N$, and $\theta$ is a finite vector of parameters. Further, $H_{t}^{1 / 2}(\theta)$ is assumed to be a $(N \times N)$ positive definite matrix, such that $H_{t}(\theta)$ is the conditional variance-covariance matrix of $r_{t}$. Both $H_{t}(\theta)$ and $r_{t}$ depend on the unknown vector $\theta$. Under this assumption of $H_{t}^{1 / 2}(\theta), H_{t}(\theta)$ also is a positive definite matrix that is given by the DCC matrix. As discussed in the introduction, following Kundu and Sarkar (2016), the conditional mean model was taken to have the STVAR representation together with a vector representing the in-mean component in two market conditions - bull and bear.

\subsection{Constant conditional correlation (CCC) and DCC representations}

Bollerslev (1990) proposed a class of MGARCH models in which the conditional correlations are assumed to be constant and hence, the conditional covariances are proportional to the product of the corresponding conditional standard deviations. These restrictions reduce the number of unknown parameters greatly, and thus simplify the estimation of the model. Such a model, referred to as the constant conditional correlation (CCC) model of $H_{t}$, based on $N$ equity returns, is defined as:

$$
H_{t}=D_{t} R D_{t}=\left(\rho_{i j} \sqrt{h_{i i, t} h_{j j, t}}\right)
$$

where $D_{t}=\operatorname{diag}\left(h_{11, t}^{1 / 2}, \ldots, h_{N N, t}^{1 / 2}\right)$ when $h_{i i, t}$ is the univariate conditional variance model for the $i^{\text {th }}$ equity returns. The usual symmetric GARCH model is used most often. However, an asymmetric GARCH specification, such as Nelson's (1991) Exponential-GARCH (EGARCH) model or Glosten et al.'s (1993) Glosten Jagannathan Runkle (GJR)-GARCH model can be used as well, especially in the case of stock returns, where asymmetry in volatility has been found to be more appropriate. Finally, $R=\left(\rho_{i j}\right)$ is a symmetric positive definite matrix the elements of which are the constant conditional correlation, $\rho_{i j}$. The original CCC model has the GARCH $(1,1)$ specification for each conditional variance in $D_{t}$, i.e.:

$h_{i i, t}=\omega_{i}+\alpha_{i} \varepsilon_{i, t-1}^{2}+\beta_{i} h_{i i, t-1}, \quad i=1, \ldots \ldots, N$. 
The $H_{t}$ matrix defined in equation (2) is positive and definite if, and only if, all the $N$ conditional variances are positive and $R$ is a positive definite matrix. The unconditional variances are obtained easily, as in the univariate case, but the unconditional covariances are difficult to compute because of the nonlinearity involved in the elements of $H_{t}$. He and Terasvirta (2002) used a VEC-type formulation for $\left(h_{11 t}, h_{22 t}, \ldots \ldots, h_{N N t}\right)^{\prime}$, to allow for interactions between the conditional variances, and referred to the resultant model as the extended CCC model.

It is quite obvious that the assumption that conditional correlations are constant is unrealistic in many empirical applications. Christodoulakis and Satchell (2002), Engle (2002), and Tse and Tsui (2002) proposed generalizations of the CCC model by making the conditional correlation matrix time-dependent in different ways. Accordingly, the DCC model is defined as:

$$
H_{t}=D_{t} R_{t} D_{t}=\left(\rho_{i j, t} \sqrt{h_{i i, t} h_{j j, t}}\right)
$$

where $R_{t}=\left(\rho_{i j, t}, \rho_{i j, t}\right)$ is the time-dependent conditional correlation. The requirement that this $H_{t}$ is positive definite is guaranteed under simple parameters conditions, as stated in Bauwens et al. (2006).

Christodoulakis and Satchell's (2002) DCC model uses the Fisher transformation of the correlation coefficient. This model, which is only applicable to a bivariate set-up, is simple to implement because the Fisher transformation guarantees the property of positive definiteness of the conditional correlation matrix. Tse and Tsui (2002) and Engle's (2002) DCC models, on the other hand, generally are multivariate in nature and are useful when modeling high-dimensional datasets. Although we considered returns on two equity markets together in this study, we used Engle's (2002) DCC model simply because it has several advantages compared to other such models. First, it is less restrictive with respect to the number of variables included in the model. Second, it accounts for heteroscedasticity by estimating the dynamic correlation coefficients of the standardized residuals. This DCC model, denoted by $D C C_{E}(1,1)$, is given as:

$R_{t}=\operatorname{diag}\left(q_{11, t}^{-1 / 2}, \ldots, q_{N N, t}^{-1 / 2}\right) Q_{t} \operatorname{diag}\left(q_{11, t}^{-1 / 2}, \ldots, q_{N N, t}^{-1 / 2}\right)$

where the $N \times N$ symmetric positive definite matrix $Q_{t}=\left(q_{i j, t}\right)$ is given by:

$Q_{t}=\left(1-\varphi_{1}-\varphi_{2}\right) \bar{Q}+\varphi_{1} \varepsilon_{t-1}^{*} \varphi_{1} \varepsilon_{t-1}^{* /}+\varphi_{2} Q_{t-1}$ 
where $\varepsilon_{t}^{*}=\left(\varepsilon_{1 t}^{*}, \ldots, \varepsilon_{N t}^{*}\right)^{\prime}, \varepsilon_{i t}^{*}=\varepsilon_{i t} / \sqrt{h_{i i, t}}, i=1, \ldots, N$, and $\varepsilon_{i t}$ is the random term associated with the given model for $r_{t}$ shown in equation (7), $\bar{Q}$ is the $N \times N$ unconditional variancecovariance matrix of $\varepsilon_{t}^{*}$, and $\varphi_{1}$ and $\varphi_{2}$ are non-negative scalar parameters that satisfy $\left(\varphi_{1}+\right.$ $\left.\varphi_{2}\right)<1$. It should be noted that, unlike Tse and Tsui's (2002) DCC model, this model has the advantage that it does not formulate the conditional correlation as a weighted sum of past correlations. Note that when $\varphi_{1}=\varphi_{2}=0$, the $D C C_{E}$ model reduces to the CCC model. Therefore, this condition can be tested to determine whether setting conditional correlations as constant is empirically relevant for a given series.

Engle (2002) considered $h_{i i, t}$ a univariate GARCH model and then stated the following conditions of the parameters for $H_{t}$ to be positive definite for all $t:(i) \omega_{i}>0,(i i) h_{i i, 0}>$ 0 , (iii) $\alpha_{i}$ and $\beta_{i}$ are such that $h_{i i, t}$ will be positive with probability one. (iv), the roots of the polynomial of the GARCH equation lie outside the unit circle, $(v) \varphi_{1}>0,(v i) \varphi_{2}>0$, and $(v i i)\left(\varphi_{1}+\varphi_{2}\right)<1$.

\subsection{The STVAR-BTGARCH-M model}

Consistent with Kundu and Sarkar (2016), we used the STVAR-BTGARCH-M model based on considerations mentioned in the previous sub-section. Thus, this model, which considers two market situations, bull and bear, has the conditional mean equation specified in equation (7) that is given by STVAR, as well as an 'in-mean' volatility component, with $H_{t}$ as given in equation (4). The underlying transition function is a continuous function $\boldsymbol{G}\left[\bar{r}_{i t}^{k}, \gamma\right]$, most often the logistic function, which changes smoothly from 0 to 1 as $\bar{r}_{\boldsymbol{i t}}^{\boldsymbol{k}}$ increases (for details, see Terasvirta, 1994), where $\bar{r}_{i t}^{k}=\frac{\sum_{j=1}^{k} r_{i, t-j}}{k}$, is the average of the past $k$ returns on the $i^{t h}$ equity market $(i=1,2)$ in our case. Hence, the logistic transition function incorporates the monotonically changing market conditions from bear to bull. Note that the bull market is characterized by $\bar{r}_{i t}^{k}>0$ and the bear market by $\bar{r}_{i t}^{k} \leq 0$. Thus, the two regimes are associated with very small and large values of the transition variable, $\bar{r}_{\boldsymbol{i}}^{\boldsymbol{k}}$, respectively. As Chen (2009) suggested, the threshold value was set to zero for both returns to define the bull and bear market conditions. Accordingly, the STVARBTGRACH-M model for this study where $N=2$, is given by:

$$
r_{t}=\left(a^{1}+B^{1} r_{t-1}+\Lambda^{1} \operatorname{vech}\left(H_{t}(\theta)\right)\right) \odot(\mathbf{1}-\boldsymbol{G}[\cdot])
$$




$$
+\left(a^{2}+B^{2} r_{t-1}+\Lambda^{2} \operatorname{vech}\left(H_{t}(\theta)\right)\right) \odot \boldsymbol{G}[\cdot]+\varepsilon_{t}
$$

where $\quad r_{t}=\left(\begin{array}{l}r_{1 t} \\ r_{2 t}\end{array}\right), a^{1}=\left(\begin{array}{l}a_{1}^{1} \\ a_{2}^{1}\end{array}\right), a^{2}=\left(\begin{array}{l}a_{1}^{2} \\ a_{2}^{2}\end{array}\right), B^{1}=\left(\begin{array}{ll}b_{11}^{1} & b_{12}^{1} \\ b_{21}^{1} & b_{22}^{1}\end{array}\right), B^{2}=\left(\begin{array}{ll}b_{11}^{2} & b_{12}^{2} \\ b_{21}^{2} & b_{22}^{2}\end{array}\right) \quad, \quad \Lambda^{1}=$ $\left(\begin{array}{lll}\lambda_{11}^{1} & \lambda_{12}^{1} & \lambda_{13}^{1} \\ \lambda_{21}^{1} & \lambda_{22}^{1} & \lambda_{23}^{1}\end{array}\right), \Lambda^{2}=\left(\begin{array}{lll}\lambda_{11}^{2} & \lambda_{12}^{2} & \lambda_{13}^{2} \\ \lambda_{21}^{2} & \lambda_{22}^{2} & \lambda_{23}^{2}\end{array}\right), H_{t}=\left(\begin{array}{ll}h_{11 t} & h_{12 t} \\ h_{12 t} & h_{22 t}\end{array}\right), \operatorname{vech}\left(H_{t}\right)=\left(\begin{array}{l}h_{11 t} \\ h_{12 t} \\ h_{22 t}\end{array}\right), \varepsilon_{t}=$ $\left(\begin{array}{l}\varepsilon_{1 t} \\ \varepsilon_{2 t}\end{array}\right), \boldsymbol{G}[\cdot]=\left(\begin{array}{l}g\left(\bar{r}_{1 t}^{k}, \gamma_{1}\right) \\ g\left(\bar{r}_{2 t}^{k}, \gamma_{2}\right)\end{array}\right)$, and $g\left(\bar{r}_{i t}^{k}, \gamma_{i}\right), i=1,2$, are the usual logistic functions with parameters $\gamma_{1}$ and $\gamma_{2}$ corresponding to the two different market conditions. $H_{t}$ is the conditional variance-covariance matrix of the DCC model as given in equation (4). All other notations have the meanings described already. Superscripts 1 and 2 refer to 'bear' and 'bull' markets, respectively. Note that in our study, we accounted for the potentially asymmetric response of volatility to positive and negative shocks on returns by assuming that the conditional variance components follow a GJR-GARCH $(p, q)$ process. In its simple form and in our context, this process is defined as:

$h_{i i, t}=\omega_{i}+\sum_{j=1}^{q} \alpha_{i j} \varepsilon_{i, t-j}^{* 2}+\sum_{j=1}^{q} d_{i j} I\left(\varepsilon_{i, t-j}^{*}<0\right) \varepsilon_{i, t-j}^{* 2}+\sum_{j=1}^{p} \beta_{i j} h_{i, t-j}$

where the indicator function, $I(\cdot)=1$ when the condition $\varepsilon_{i, t-j}^{*}<0$ holds; otherwise $I(\cdot)=0$. The parameter $d_{i j}$ measures the leverage effect. The reason for assuming this form for asymmetric volatility is that volatility of returns often has been found to be asymmetric in financial markets (Kundu and Sarkar, 2016).

The estimation of the STVAR-BTGARCH-M model is conducted via the maximum likelihood (ML) method. A useful feature of the DCC model is that this can be estimated consistently using a two-step procedure (e.g., see Engle and Sheppard, 2001; Bauwens et al., 2006). Assuming bivariate normality for the conditional distribution of $\varepsilon_{t} \mid \psi_{t-1}$, where $\psi_{t-1}$ is the set of past information on all variables up to time $t-1, \varepsilon_{t} \mid \psi_{t-1} \sim N\left(0, H_{t}\right)$, the log-likelihood function (up to a constant) based on $T$ observations, is given as:

$$
L(\theta)=-\frac{1}{2} \sum_{t=1}^{T}\left(\ln \left|H_{t}\right|+\varepsilon_{t}^{\prime} H_{t}^{-1} \varepsilon_{t}\right)
$$


Obtaining the ML estimate of the parameter vector $\theta$ requires maximizing this log-likelihood function. The objective function involved is evidently highly nonlinear, and the codes required were obtained from Kundu and Sarkar (2016).

Several levels of $k$ were considered when we chose the one appropriate for the threshold variable $\bar{r}_{i t}^{k}$, and for each of those values, the maximized log-likelihood value was obtained based on a similar model at the univariate level. The value of $k$ for which the value of the maximized $\log$ likelihood for the univariate model was found to be the highest was taken as the value of $k$.

\subsection{Hypotheses and the Wald test $t^{3}$}

We performed the Wald test to assess the significance of the own and cross spillover effects of returns, volatility and the 'in-mean' component involving Bitcoin and each of the eight markets studied (MSCI World, MSCI Emerging markets, MSCI China, Commodity, energy, gold, US dollar, and US treasury). In doing so, we accounted for the bull and bear market conditions by placing appropriate restrictions on the relevant parameters in equation (7). We formulate below the different null hypotheses that specify the absence of each of three different kinds of spillovers or transmissions for Bitcoin and other markets, as well as the equality of spillovers in bull and bear market conditions.

\section{Tests of spillovers in conditional mean}

(a) $H_{01}^{a}$ : No spillovers in means from other markets to Bitcoin market in both bull and bear market movements, i.e., $b_{12}^{1}=b_{12}^{2}=0$.

(b) $H_{01}^{b}$ : No spillovers in mean from Bitcoin market to other markets in both bull and bear market movements, i.e., $b_{21}^{1}=b_{21}^{2}=0$.

2. Tests of equality of spillovers in bull and bear market movements for Bitcoin and other markets

(a) $H_{02}^{a}$ : Equality of spillovers in mean in bull and bear market conditions from other markets to Bitcoin market, i.e., $b_{12}^{1}=b_{12}^{2}$.

\footnotetext{
${ }^{3}$ Before discussing the different hypotheses of interest pertaining to the STVAR-BTGARCH-M model, we tested for linearity vs. non-linearity in the data generating process using a bivariate framework consistent with Camacho (2004); see Tables A.3 and A.4 in the Appendix. The test enabled us to determine which of the two standard transition functions - logistic and exponential—was appropriate for the underlying model.
} 
(b) $H_{02}^{b}$ : Equality of spillovers in means in bull and bear market conditions from Bitcoin market to other markets, i.e., $b_{21}^{1}=b_{21}^{2}$.

3. Tests of no BTGARCH-M effect from one market to another

(a) Equality of the own volatility spillover on Bitcoin returns in bull and bear markets, i.e., $H_{03}^{a}: \lambda_{11}^{1}=\lambda_{11}^{2}$.

(b) Equality of volatility spillover of other markets on Bitcoin returns in bull and bear markets, i.e., $H_{03}^{b}: \lambda_{13}^{1}=\lambda_{13}^{2}$.

(c) Equality of the own volatility spillover on other market returns in bull and bear markets, i.e., $H_{03}^{c}: \lambda_{23}^{1}=\lambda_{23}^{2}$.

(d) Equality of volatility spillover of Bitcoin market on other returns in bull and bear markets, i.e., $H_{03}^{d}: \lambda_{21}^{1}=\lambda_{21}^{2}$.

4. Test of equality of each of the parameters of BTGARCH-M in bull and bear market movements

$$
H_{04}: \lambda_{11}^{1}=\lambda_{11}^{2} ; \lambda_{12}^{1}=\lambda_{12}^{2} ; \lambda_{13}^{1}=\lambda_{13}^{2} ; \lambda_{21}^{1}=\lambda_{21}^{2} ; \lambda_{22}^{1}=\lambda_{22}^{2} ; \lambda_{23}^{1}=\lambda_{23}^{2} .
$$

5. Test of asymmetric volatility (because of leverage effect) of Bitcoin and other markets

No asymmetric volatility, i.e., $H_{05}: d_{1 j}=d_{2 j}=0$ for all $j$.

6. Test of equality of dynamic conditional correlation

No dynamic conditional correlation, i.e., $H_{06}: \varphi_{1}=\varphi_{2}=0$.

\section{Data and Empirical results}

\subsection{Data}

Our dataset covered data prices of Bitcoin and proxies of four asset classes (stocks, commodities, currencies, and bonds): MSCI World, MSCI Emerging markets, MSCI China, S\&P GSCI Commodity, S\&P GSCI energy, one ounce of gold, US dollar index, and US 10-year treasury yields. Bitcoin prices were obtained from CoinDesk, which calculates and publishes the average price of Bitcoin in leading Bitcoin exchanges (Bouri et al., 2017b). Data on the four asset classes were extracted from DataStream. The sample period was July 19, 2010 to October 31, 2017, 
where the starting date depicts the availability of Bitcoin prices. The statistics of the daily logarithmic returns (Table 1) revealed that Bitcoin has both the highest average return and standard deviation. All return series are skewed negatively, except for the US treasury and US Dollar. All series have a kurtosis value in excess of that in a normal distribution. The JarqueBera test showed that all return series depart from the normal distribution. There is evidence of significant conditional heteroscedasticity, as suggested by the ARCH test. Results from two-unit root tests (Augmented Dickey fuller (ADF) and Phillips Perron (PP)) indicated that all return series are stationary. We considered the presence of multiple structural breaks via Bai and Perron's (2003) test, the results of which are reported in Table 2A in the Appendix. The results provided evidence of structural breaks, particularly when the pair of variables was considered. We also found evidence of nonlinearity, especially in the relation between Bitcoin and each of the eight markets studied. The results of Brock et al.'s (1996) BDS tests are reported in Table 1A in the Appendix.

Table 1. Summary statistics of daily returns

\begin{tabular}{|l|c|c|c|c|c|c|c|c|}
\hline & Mean & SD & Skewness & Kurtosis & Jarque-Bera & ADF & PP & LM-ARCH \\
\hline Bitcoin & 0.594 & 6.508 & -0.001 & 12.576 & $7263.237^{*}$ & $-41.956^{*}$ & $-42.801^{*}$ & $23.590^{*}$ \\
\hline MSCI World & 0.033 & 0.818 & -0.564 & 7.997 & $2079.205^{*}$ & $-38.546^{*}$ & $-38.368^{*}$ & $34.775^{*}$ \\
\hline MSC Emerging Markets & 0.009 & 0.956 & -0.403 & 6.152 & $838.506^{*}$ & $-34.458^{*}$ & $-34.075^{*}$ & $29.649^{*}$ \\
\hline MSCI China & 0.019 & 1.262 & -0.175 & 6.268 & $855.918^{*}$ & $-41.316^{*}$ & $-41.290^{*}$ & $28.317^{*}$ \\
\hline Commodity & -0.010 & 1.184 & -0.169 & 5.615 & $550.731^{*}$ & $-45.339^{*}$ & $-45.306^{*}$ & $11.757^{*}$ \\
\hline Energy & -0.040 & 1.703 & -0.046 & 6.198 & $810.607^{*}$ & $-45.825^{*}$ & $-45.768^{*}$ & $20.449^{*}$ \\
\hline Gold & 0.003 & 1.027 & -0.811 & 10.933 & $5194.346^{*}$ & $-44.240^{*}$ & $-44.341^{*}$ & $4.068^{*}$ \\
\hline US Dollar Index & 0.007 & 0.463 & 0.062 & 4.590 & $201.487^{*}$ & $-44.008^{*}$ & $-44.010^{*}$ & $4.750^{*}$ \\
\hline US Treasury & -0.011 & 2.309 & 0.122 & 4.646 & $219.521^{*}$ & $-46.189^{*}$ & $-46.359^{*}$ & $15.572^{*}$ \\
\hline
\end{tabular}

Note: This table presents the summary statistics of daily returns and unit root tests. The data span from July 19, 2010 to October 31, 2017. The Jarque-Bera test assesses the normality of the return distribution; LM-ARCH statistics are for Engle's Lagrange Multiplier heteroscedasticity test under the null hypothesis of no ARCH effects; Augmented Dickey fuller (ADF) and Phillips Perron (PP) tests were used to test the null hypothesis that the series is integrated on the order of one; * denotes statistical significance at $1 \%$.

\subsection{Empirical results}

\subsubsection{Return spillovers in bull and bear markets}

Table 2 presents the results of the return spillover effects between the Bitcoin market and each of the eight markets studied. The return spillover effects from each of the eight markets to Bitcoin and Bitcoin to each of the eight markets are captured by the parameter $b_{12}^{i}\left(b_{21}^{i}\right)$; where $i=1,2$ represents bear and bull markets, respectively. 
Return spillovers from world and emerging markets to Bitcoin are positive in bull markets, but negative in bear markets. In contrast, the spillover from China to Bitcoin is positive regardless of market conditions. In the opposite relation, there is a positive return spillover from Bitcoin to world, emerging, and Chinese stock markets in bear markets only, while negative return spillovers from Bitcoin to world equities exist in bull markets.

The results also indicated that commodity, energy, and bonds have positive return spillovers to the Bitcoin market in both market conditions. Conversely, return spillovers from Bitcoin to commodity, energy, gold, and bonds are positive in bear markets, while they are negative in bull markets in the cases of energy, gold, and bonds only. Return spillovers from the US dollar to Bitcoin are positive in bear markets, but negative in bull markets. Conversely, Bitcoin has no significant return spillover effect on the US dollar in both bull and bear market conditions.

Taken together, our findings suggested that there are asymmetric return spillovers in bull and bear market conditions between Bitcoin and most of the assets studied, particularly from that of Bitcoin to the other markets. However, it appears that Bitcoin returns receive more than they transmit, suggesting that investors and policymakers interested in the Bitcoin market should consider the returns and state of other markets carefully to predict Bitcoin returns, particularly during bear market conditions.

Table 2. Estimation of the mean parameters

\begin{tabular}{|c|c|c|c|c|c|c|c|c|c|c|c|c|}
\hline & \multicolumn{6}{|c|}{ Bear market } & \multicolumn{6}{|c|}{ Bull market } \\
\hline & $a_{1}^{1}$ & $b_{11}^{1}$ & $b_{12}^{1}$ & $a_{2}^{1}$ & $b_{21}^{1}$ & $b_{22}^{1}$ & $a_{1}^{2}$ & $b_{11}^{2}$ & $b_{12}^{2}$ & $a_{2}^{2}$ & $b_{21}^{2}$ & $b_{22}^{2}$ \\
\hline [Bitcoin, MSCI & $-0.15^{*}$ & $-0.06 *$ & $-0.03 * * *$ & $0.15^{*}$ & $0.06^{*}$ & $0.28 *$ & $0.45^{*}$ & $0.07 *$ & $0.24 *$ & $-0.15^{*}$ & $-0.04 *$ & $-0.04 * *$ \\
\hline world] & $(0.00)$ & $(0.00)$ & $(0.08)$ & $(0.00)$ & $(0.00)$ & $(0.00)$ & $(0.00)$ & $(0.00)$ & $(0.00)$ & $(0.00)$ & $(0.00)$ & $(0.03)$ \\
\hline [Bitcoin, MSCI & $-0.98 *$ & $-0.02 *$ & 0.01 & -0.00 & $0.01 * *$ & $0.26^{*}$ & $0.24 *$ & $0.08 *$ & $0.12 *$ & -0.00 & -0.00 & $0.16^{*}$ \\
\hline emerging markets] & $(0.00)$ & $(0.01)$ & $(0.44)$ & $(0.89)$ & $(0.04)$ & $(0.00)$ & $(0.00)$ & $(0.00)$ & $(0.00)$ & $(0.85)$ & $(0.34)$ & $(0.00)$ \\
\hline [Bitcoin, MSCI & $-0.07 *$ & $-0.03 *$ & $0.06 *$ & $0.07 *$ & $0.02 *$ & $0.06^{*}$ & $0.17 *$ & $0.10 *$ & $0.11 *$ & $0.01 *$ & -0.01 & $0.01 * * *$ \\
\hline China] & $(0.00)$ & $(0.00)$ & $(0.00)$ & $(0.00)$ & $(0.00)$ & $(0.00)$ & $(0.00)$ & $(0.00)$ & $(0.00)$ & $(0.09)$ & $(0.19)$ & $(0.07)$ \\
\hline [Bitcoin, & $-0.06^{*}$ & $-0.03 *$ & $0.08 *$ & 0.01 & $0.02 *$ & $-0.04 *$ & $0.18 *$ & $0.12 *$ & $0.15 *$ & -0.00 & -0.01 & $-0.03 *$ \\
\hline commodity] & $(0.00)$ & $(0.00)$ & $(0.00)$ & $(0.23)$ & $(0.00)$ & $(0.00)$ & $(0.00)$ & $(0.00)$ & $(0.00)$ & $(0.92)$ & $(0.10)$ & $(0.00)$ \\
\hline [Bitcoin, energy] & $-0.08^{*}$ & $-0.05 *$ & $0.05^{*}$ & 0.02 & $0.03^{*}$ & $-0.03 *$ & $0.18 *$ & $0.11 *$ & $0.10^{*}$ & -0.00 & $-0.02 *$ & -0.02 \\
\hline & $(0.00)$ & $(0.00)$ & $(0.00)$ & $(0.22)$ & $(0.00)$ & $(0.00)$ & $(0.00)$ & $(0.00)$ & $(0.00)$ & $(0.62)$ & $(0.00)$ & $(0.17)$ \\
\hline [Bitcoin, Gold] & $-0.18^{*}$ & $-0.03 *$ & $0.24 *$ & 0.02 & $0.02 * * *$ & 0.01 & $0.47 *$ & $0.08 *$ & $0.33 *$ & $-0.03^{*}$ & $-0.02 * * *$ & -0.00 \\
\hline & $(0.00)$ & $(0.00)$ & $(0.00)$ & $(0.16)$ & $(0.06)$ & $(0.36)$ & $(0.00)$ & $(0.01)$ & $(0.00)$ & $(0.00)$ & $(0.08)$ & $(0.86)$ \\
\hline [Bitcoin, US dollar] & $-0.58 *$ & 0.01 & $0.08 *$ & -0.05 & 0.01 & $0.15 *$ & $0.74 *$ & $0.10 * *$ & $-0.19 *$ & -0.00 & -0.02 & $-0.16^{*}$ \\
\hline & $(0.00)$ & $(0.62)$ & $(0.00)$ & $(0.38)$ & $(0.29)$ & $(0.00)$ & $(0.00)$ & $(0.02)$ & $(0.00)$ & $(0.93)$ & $(0.18)$ & $(0.00)$ \\
\hline [Bitcoin, US & $0.03 *$ & $-0.04 *$ & $0.04 *$ & $0.09 *$ & $0.03 *$ & $-0.06^{*}$ & $0.13^{*}$ & $0.08 *$ & $0.10^{*}$ & $0.04 *$ & $-0.02 *$ & $-0.03 *$ \\
\hline Treasury] & $(0.00)$ & $(0.00)$ & $(0.00)$ & $(0.00)$ & $(0.00)$ & $(0.00)$ & $(0.00)$ & $(0.00)$ & $(0.00)$ & $(0.00)$ & (0.01) & $(0.00)$ \\
\hline
\end{tabular}

Note: $p$-values are in parentheses : *,**, and *** denote statistical significance at the $1 \%, 5 \%$, and $10 \%$ levels, respectively. 


\subsubsection{Volatility-return relation in bull and bear markets (volatility-in-mean parameters)}

In this section, we present the results of the own and cross market volatility-returns relations in bull and bear markets (Table 3 ).

\section{The own market risk-returns relation}

The own risk-returns relation for the Bitcoin market (each of the eight markets) is captured by $\lambda_{11}^{i}\left(\lambda_{23}^{i}\right)$. In the case of Bitcoin, the own volatility-return relation in all pairs involving Bitcoin returns is positive regardless of market conditions. For each of the other eight markets, the own risk-return relation in world, emerging, and Chinese markets also is positive in both market conditions. However, in the case of commodities, the relation is negative in bear markets, but positive in bear markets. For both gold and the US dollar, the own volatility-return relation is positive in bear markets and negative in bull markets. In the cases of energy and bonds, the relation is insignificant in both market conditions.

\section{Cross market risk-returns relation}

We now consider the way in which the volatility of one Bitcoin affects the returns of another market and the converse in both market conditions. The cross risk-returns relation is identified by the two parameters $\lambda_{13}^{i}$ and $\lambda_{21}^{i}$. The former parameter captures the risk effect of each of the eight markets on Bitcoin returns, while the latter captures the effect of Bitcoin risk on the returns of each of the eight markets. We found that Bitcoin returns are affected positively by the volatility of all markets studied during bull markets. In contrast, during bear markets, Bitcoin returns are affected positively by the volatility of Chinese equities, commodity, and the US dollar, but negatively by the volatility of world and emerging markets and that of gold and bond markets. 
Table 3. Estimation of the volatility-in-mean parameters

\begin{tabular}{|c|c|c|c|c|c|c|c|c|c|c|c|c|}
\hline & \multicolumn{6}{|c|}{ Bear market } & \multicolumn{6}{|c|}{ Bull market } \\
\hline & $\lambda_{11}^{1}$ & $\lambda_{12}^{1}$ & $\lambda_{13}^{1}$ & $\lambda_{21}^{1}$ & $\lambda_{22}^{1}$ & $\lambda_{23}^{1}$ & $\lambda_{11}^{2}$ & $\lambda_{12}^{2}$ & $\lambda_{13}^{2}$ & $\lambda_{21}^{2}$ & $\lambda_{22}^{2}$ & $\lambda_{23}^{2}$ \\
\hline $\begin{array}{l}\text { [Bitcoin, MSCI } \\
\text { world] }\end{array}$ & $\begin{array}{l}0.01 * \\
(0.00)\end{array}$ & $\begin{array}{r}-0.01 * \\
(0.00)\end{array}$ & $\begin{array}{r}-0.07^{*} \\
(0.00)\end{array}$ & $\begin{array}{r}-0.00 \\
(0.35)\end{array}$ & $\begin{array}{l}0.10^{*} \\
(0.00)\end{array}$ & $\begin{array}{l}0.11 * \\
(0.00)\end{array}$ & $\begin{array}{r}0.00 \\
(0.43)\end{array}$ & $\begin{array}{l}0.09^{*} \\
(0.00)\end{array}$ & $\begin{array}{l}0.05^{*} \\
(0.00)\end{array}$ & $\begin{array}{r}0.00 \\
(0.41)\end{array}$ & $\begin{array}{r}-0.09^{*} \\
(0.00)\end{array}$ & $\begin{array}{l}0.10^{*} \\
(0.00)\end{array}$ \\
\hline $\begin{array}{l}\text { [Bitcoin, MSCI } \\
\text { emerging markets] }\end{array}$ & $\begin{array}{l}0.01 * \\
(0.00)\end{array}$ & $\begin{array}{r}-0.07^{*} \\
(0.00)\end{array}$ & $\begin{array}{r}-0.06^{*} \\
(0.00)\end{array}$ & $\begin{array}{r}0.00 \\
(0.68)\end{array}$ & $\begin{array}{r}0.01 \\
(0.14)\end{array}$ & $\begin{array}{l}0.06^{*} \\
(0.00)\end{array}$ & $\begin{array}{l}0.00^{*} \\
(0.01)\end{array}$ & $\begin{array}{l}-0.01 \\
(0.17)\end{array}$ & $\begin{array}{r}0.05 * * * \\
(0.08)\end{array}$ & $\begin{array}{r}-0.00 \\
(0.16)\end{array}$ & $\begin{array}{r}-0.13^{*} \\
(0.00)\end{array}$ & $\begin{array}{l}0.05^{*} \\
(0.00)\end{array}$ \\
\hline $\begin{array}{l}\text { [Bitcoin, MSCI } \\
\text { China] }\end{array}$ & $\begin{array}{l}0.01^{*} \\
(0.00)\end{array}$ & $\begin{array}{r}-0.00 \\
(0.48) \\
\end{array}$ & $\begin{array}{r}0.02 * * \\
(0.02)\end{array}$ & $\begin{array}{r}0.00 \\
(0.82) \\
\end{array}$ & $\begin{array}{l}0.03 * \\
(0.00) \\
\end{array}$ & $\begin{array}{r}-0.01 \\
(0.31) \\
\end{array}$ & $\begin{array}{l}0.00^{*} \\
(0.00) \\
\end{array}$ & $\begin{array}{l}0.07^{*} \\
(0.00) \\
\end{array}$ & $\begin{array}{l}0.08 * \\
(0.00) \\
\end{array}$ & $\begin{array}{r}-0.00 \\
(0.12) \\
\end{array}$ & $\begin{array}{r}-0.11^{*} \\
(0.00)\end{array}$ & $\begin{array}{r}0.03^{*} \\
(0.00) \\
\end{array}$ \\
\hline $\begin{array}{l}\text { [Bitcoin, } \\
\text { commodity] }\end{array}$ & $\begin{array}{l}0.01^{*} \\
(0.00)\end{array}$ & $\begin{array}{r}-0.01 \\
(0.25)\end{array}$ & $\begin{array}{r}0.03^{*} \\
(0.00)\end{array}$ & $\begin{array}{r}0.00 \\
(0.40)\end{array}$ & $\begin{array}{r}0.02 * * \\
(0.02)\end{array}$ & $\begin{array}{l}-0.07 * \\
(0.00)\end{array}$ & $\begin{array}{r}0.00 * * * * \\
(0.07)\end{array}$ & $\begin{array}{l}0.08^{*} \\
(0.00)\end{array}$ & $\begin{array}{l}0.07 * \\
(0.00)\end{array}$ & $\begin{array}{r}-0.00 \\
(0.60)\end{array}$ & $\begin{array}{r}-0.13^{*} \\
(0.00)\end{array}$ & $\begin{array}{l}0.05^{*} \\
(0.00)\end{array}$ \\
\hline [Bitcoin, energy] & $\begin{array}{l}0.01^{*} \\
(0.00)\end{array}$ & $\begin{array}{r}-0.01 \\
(0.14)\end{array}$ & $\begin{array}{r}-0.05^{*} \\
(0.00)\end{array}$ & $\begin{array}{r}0.00 \\
(0.82) \\
\end{array}$ & $\begin{array}{l}0.02 * \\
(0.00)\end{array}$ & $\begin{array}{r}0.00 \\
(0.92)\end{array}$ & $\begin{array}{r}0.00 * * * * \\
(0.07) \\
\end{array}$ & $\begin{array}{l}0.08^{*} \\
(0.00)\end{array}$ & $\begin{array}{l}0.07 * \\
(0.00)\end{array}$ & $\begin{array}{r}-0.00 \\
(0.55)\end{array}$ & $\begin{array}{r}-0.13^{*} \\
(0.00)\end{array}$ & $\begin{array}{r}-0.00 \\
(0.95) \\
\end{array}$ \\
\hline [Bitcoin, Gold] & $\begin{array}{l}0.02 * \\
(0.00) \\
\end{array}$ & $\begin{array}{r}-0.03^{*} \\
(0.00) \\
\end{array}$ & $\begin{array}{r}-0.25^{*} \\
(0.00) \\
\end{array}$ & $\begin{array}{l}-0.00 * \\
(0.00) \\
\end{array}$ & $\begin{array}{l}0.11 * \\
(0.00) \\
\end{array}$ & $\begin{array}{l}0.16^{*} \\
(0.00) \\
\end{array}$ & $\begin{array}{r}-0.00^{*} \\
(0.00) \\
\end{array}$ & $\begin{array}{l}0.09^{*} \\
(0.00) \\
\end{array}$ & $\begin{array}{l}0.29 * \\
(0.00) \\
\end{array}$ & $\begin{array}{l}0.00 * \\
(0.00) \\
\end{array}$ & $\begin{array}{r}-0.12 * \\
(0.00) \\
\end{array}$ & $\begin{array}{r}-0.14^{*} \\
(0.00) \\
\end{array}$ \\
\hline [Bitcoin, US dollar] & $\begin{array}{l}0.02 * \\
(0.00)\end{array}$ & $\begin{array}{r}0.05^{*} \\
(0.00)\end{array}$ & $\begin{array}{r}0.00 \\
(0.15)\end{array}$ & $\begin{array}{c}0.07 * \\
(0.00)\end{array}$ & $\begin{array}{l}0.15^{*} \\
(0.00) \\
\end{array}$ & $\begin{array}{c}0.15^{*} \\
(0.00)\end{array}$ & $\begin{array}{r}-0.00 \\
(0.19) \\
\end{array}$ & $\begin{array}{r}0.00 \\
(0.45) \\
\end{array}$ & $\begin{array}{l}0.09 * \\
(0.00) \\
\end{array}$ & $\begin{array}{r}-0.00 \\
(0.21)\end{array}$ & $\begin{array}{l}0.16^{*} \\
(0.00)\end{array}$ & $\begin{array}{l}0.20^{*} \\
(0.00)\end{array}$ \\
\hline $\begin{array}{l}\text { [Bitcoin, US } \\
\text { Treasury] }\end{array}$ & $\begin{array}{c}0.01 * \\
(0.00) \\
\end{array}$ & $\begin{array}{r}-0.08 * \\
(0.00) \\
\end{array}$ & $\begin{array}{r}-0.05^{*} \\
(0.00) \\
\end{array}$ & $\begin{array}{c}-0.00 * \\
(0.00) \\
\end{array}$ & $\begin{array}{l}0.02 * \\
(0.00) \\
\end{array}$ & $\begin{array}{r}0.00 \\
(0.58) \\
\end{array}$ & $\begin{array}{c}0.00^{*} \\
(0.00) \\
\end{array}$ & $\begin{array}{r}0.00 \\
(0.97) \\
\end{array}$ & $\begin{array}{l}0.08 * \\
(0.00) \\
\end{array}$ & $\begin{array}{c}0.00 * \\
(0.00) \\
\end{array}$ & $\begin{array}{r}-0.12 * \\
(0.00) \\
\end{array}$ & $\begin{array}{r}-0.01 \\
(0.26) \\
\end{array}$ \\
\hline
\end{tabular}

Note: $p$-values indicated as above.

With respect to the effect of Bitcoin volatility on the returns of the eight markets studied, the results indicated significant effects in three of eight cases. Specifically, the returns of gold and bonds are affected negatively (positively) by the volatility of the Bitcoin market in bear (bull) markets, while US dollar returns are affected positively in bear markets. Thus, the volatility effect of other markets on Bitcoin returns is more important than is Bitcoin's volatility effect on the other markets, regardless of market conditions. Specifically, the effect on Bitcoin is positive during bull markets, while it is mixed during the down market. Largely, it is negative, except for the cases of Chinese equities, commodities, and the US dollar. With respect to magnitude, the negative effect of the gold market on that of Bitcoin is the strongest.

\subsubsection{Parameters of smoothness, GJR-GARCH, and DCC models}

To justify the appropriateness of our reliance on the smooth transition, asymmetric GARCH model, and DCC specification further, we report in Table 4 the results of several parameter estimates. Regarding the parameters of smoothness $\left(\gamma_{1}\right.$ and $\left.\gamma_{2}\right)$, the results were positive for every dataset. The values of these two parameters were neither close to zero nor very high, which implies that the transition from a bear to a bull market situation is smooth. Hence, the validity of the smooth transition in the conditional mean model was justified empirically for all cases. 
Table 4. Estimation of the parameters of smoothness, GJR-GARCH and DCC models

\begin{tabular}{|c|c|c|c|c|c|c|c|c|c|c|c|c|}
\hline & & & & & & & & & & & & \\
\hline [Bitcoin, MSCI & $2.58^{* *}$ & $2.01 *$ & $0.70^{*}$ & $0.04 *$ & $0.15^{*}$ & $0.04 *$ & $-0.05^{*}$ & $0.23 *$ & $0.87 *$ & $0.74 *$ & $0.16^{*}$ & $0.29 *$ \\
\hline world] & $(0.00)$ & $(0.00)$ & $(0.00)$ & $(0.00)$ & $(0.00)$ & $(0.00)$ & $(0.00)$ & $(0.00)$ & $(0.00)$ & $(0.00)$ & $(0.00)$ & $(0.00)$ \\
\hline $\begin{array}{l}\text { [Bitcoin, MSCI } \\
\text { emerging markets] }\end{array}$ & $\begin{array}{l}3.59^{*} \\
(0.00)\end{array}$ & $\begin{array}{l}2.11^{*} \\
(0.00)\end{array}$ & $\begin{array}{l}0.78^{*} \\
(0.00)\end{array}$ & $\begin{array}{l}0.03^{*} \\
(0.00)\end{array}$ & $\begin{array}{l}0.16^{*} \\
(0.00)\end{array}$ & $\begin{array}{r}0.00 \\
(0.56)\end{array}$ & $\begin{array}{r}-0.06^{*} \\
(0.00)\end{array}$ & $\begin{array}{l}0.12^{*} \\
(0.00)\end{array}$ & $\begin{array}{l}0.86^{*} \\
(0.00)\end{array}$ & $\begin{array}{l}0.88^{*} \\
(0.00)\end{array}$ & $\begin{array}{l}0.14^{*} \\
(0.00)\end{array}$ & $\begin{array}{l}0.31^{*} \\
(0.00)\end{array}$ \\
\hline $\begin{array}{l}\text { [Bitcoin, MSCI } \\
\text { China] }\end{array}$ & $\begin{array}{l}2.48 * \\
(0.00)\end{array}$ & $\begin{array}{l}2.12^{*} \\
(0.00)\end{array}$ & $\begin{array}{l}0.67 * \\
(0.00)\end{array}$ & $\begin{array}{l}0.06^{*} \\
(0.00)\end{array}$ & $\begin{array}{l}0.16^{*} \\
(0.00)\end{array}$ & $\begin{array}{l}0.02 * \\
(0.01)\end{array}$ & $\begin{array}{r}-0.06^{*} \\
(0.00)\end{array}$ & $\begin{array}{l}0.08^{*} \\
(0.00)\end{array}$ & $\begin{array}{l}0.86^{*} \\
(0.00)\end{array}$ & $\begin{array}{l}0.89^{*} \\
(0.00)\end{array}$ & $\begin{array}{l}0.14^{*} \\
(0.00)\end{array}$ & $\begin{array}{l}0.29^{*} \\
(0.00)\end{array}$ \\
\hline $\begin{array}{l}\text { [Bitcoin, } \\
\text { commodity] }\end{array}$ & $\begin{array}{l}2.51 * \\
(0.00) \\
\end{array}$ & $\begin{array}{l}2.14^{*} \\
(0.00)\end{array}$ & $\begin{array}{l}0.70^{*} \\
(0.00) \\
\end{array}$ & $\begin{array}{l}0.06^{*} \\
(0.00) \\
\end{array}$ & $\begin{array}{l}0.16^{*} \\
(0.00) \\
\end{array}$ & $\begin{array}{l}0.05^{*} \\
(0.00) \\
\end{array}$ & $\begin{array}{r}-0.06^{*} \\
(0.00) \\
\end{array}$ & $\begin{array}{l}0.10^{*} \\
(0.00)\end{array}$ & $\begin{array}{l}0.86^{*} \\
(0.00) \\
\end{array}$ & $\begin{array}{l}0.85^{*} \\
(0.00) \\
\end{array}$ & $\begin{array}{l}0.10^{*} \\
(0.00)\end{array}$ & $\begin{array}{l}0.29^{*} \\
(0.00) \\
\end{array}$ \\
\hline [Bitcoin, energy] & $\begin{array}{l}2.47 * \\
(0.00) \\
\end{array}$ & $\begin{array}{l}2.10^{*} \\
(0.00)\end{array}$ & $\begin{array}{c}0.70^{*} \\
(0.00) \\
\end{array}$ & $\begin{array}{r}0.06^{*} \\
(0.00) \\
\end{array}$ & $\begin{array}{r}0.16^{*} \\
(0.00) \\
\end{array}$ & $\begin{array}{l}0.04 * \\
(0.00) \\
\end{array}$ & $\begin{array}{r}-0.06^{*} \\
(0.00) \\
\end{array}$ & $\begin{array}{r}0.09 * \\
(0.00) \\
\end{array}$ & $\begin{array}{r}0.86^{*} \\
(0.00) \\
\end{array}$ & $\begin{array}{r}0.88^{*} \\
(0.00) \\
\end{array}$ & $\begin{array}{l}0.12^{*} \\
(0.00)\end{array}$ & $\begin{array}{l}0.30^{*} \\
(0.00) \\
\end{array}$ \\
\hline [Bitcoin, Gold] & $\begin{array}{l}2.54 * \\
(0.00)\end{array}$ & $\begin{array}{l}2.08^{*} \\
(0.00)\end{array}$ & $\begin{array}{l}1.03 * \\
(0.00)\end{array}$ & $\begin{array}{l}0.04 * \\
(0.00)\end{array}$ & $\begin{array}{l}0.22 * \\
(0.00)\end{array}$ & $\begin{array}{l}0.06^{*} \\
(0.00)\end{array}$ & $\begin{array}{r}-0.08^{*} \\
(0.00)\end{array}$ & $\begin{array}{r}0.00 \\
(0.41)\end{array}$ & $\begin{array}{l}0.82 * \\
(0.00)\end{array}$ & $\begin{array}{l}0.88^{*} \\
(0.00)\end{array}$ & $\begin{array}{l}0.05^{*} \\
(0.01)\end{array}$ & $\begin{array}{l}0.32 * \\
(0.00) \\
\end{array}$ \\
\hline $\begin{array}{l}\text { [Bitcoin, US } \\
\text { dollar] }\end{array}$ & $\begin{array}{l}2.71 * \\
(0.00) \\
\end{array}$ & $\begin{array}{l}2.03^{*} \\
(0.00) \\
\end{array}$ & $\begin{array}{l}2.72 * \\
(0.00) \\
\end{array}$ & $\begin{array}{c}0.03 * \\
(0.00) \\
\end{array}$ & $\begin{array}{c}0.30^{*} \\
(0.00) \\
\end{array}$ & $\begin{array}{l}0.06^{*} \\
(0.00) \\
\end{array}$ & $\begin{array}{r}-0.08 * \\
(0.01) \\
\end{array}$ & $\begin{array}{r}0.02 \\
(0.35) \\
\end{array}$ & $\begin{array}{l}0.70^{*} \\
(0.00) \\
\end{array}$ & $\begin{array}{c}0.77^{*} \\
(0.00) \\
\end{array}$ & $\begin{array}{l}0.01 * \\
(0.00) \\
\end{array}$ & $\begin{array}{l}0.29^{*} \\
(0.00) \\
\end{array}$ \\
\hline $\begin{array}{l}\text { [Bitcoin, US } \\
\text { Treasury] }\end{array}$ & $\begin{array}{l}2.61 * \\
(0.00) \\
\end{array}$ & $\begin{array}{l}2.10^{*} \\
(0.00)\end{array}$ & $\begin{array}{l}0.79 * \\
(0.00) \\
\end{array}$ & $\begin{array}{c}0.28^{*} \\
(0.00) \\
\end{array}$ & $\begin{array}{l}0.19^{*} \\
(0.00) \\
\end{array}$ & $\begin{array}{c}0.06^{*} \\
(0.00) \\
\end{array}$ & $\begin{array}{c}-0.08^{*} \\
(0.00) \\
\end{array}$ & $\begin{array}{c}0.04^{*} \\
(0.00) \\
\end{array}$ & $\begin{array}{c}0.85^{*} \\
(0.00) \\
\end{array}$ & $\begin{array}{l}0.86^{*} \\
(0.00) \\
\end{array}$ & $\begin{array}{l}0.14^{*} \\
(0.00) \\
\end{array}$ & $\begin{array}{l}0.31^{*} \\
(0.00) \\
\end{array}$ \\
\hline
\end{tabular}

Note: $p$-values as above.

With respect to the behavior of the conditional variance model, BTGARCH, we found that all parameters in the GARCH component of the model $\left(\alpha_{1}, \alpha_{2}, \beta_{1}\right.$, and $\left.\beta_{2}\right)$ were significant, except for $\alpha_{2}$ in one dataset (Bitcoin and MSCI emerging markets). The two coefficients that capture asymmetry in the conditional variance $\left(d_{1 j}\right.$ and $\left.d_{2 j}\right)$ were highly significant in all cases, except for Bitcoin-Gold and Bitcoin-US dollar, where $d_{2 j}$ was insignificant. Thus, consideration of asymmetry in the volatility-return relation between the Bitcoin market and other markets was established empirically. Further, we found that the coefficients involved in the dynamic conditional correlation $\left(\varphi_{1}\right.$ and $\left.\varphi_{2}\right)$ were significant in all cases, which confirms that the DCC modeling approach is useful in explaining the volatility dynamics between Bitcoin and the other markets.

\subsubsection{Results of the main hypotheses tests}

We now turn our attention to Table 5, which provides the results of the tests of the hypotheses formulated in section 3.4. The entries in columns 1 and 2 show that the null hypothesis of "no spillover in mean' could be rejected in all but two cases, the mean spillover effect from Bitcoin returns to MSCI emerging markets returns and Gold returns.

The null hypotheses of equality in the mean spillover effects from the other asset returns to Bitcoin returns in the bull and bear regimes (i.e., column 3) were rejected for all cases, while the 
null hypotheses of equality in the mean spillover effect from Bitcoin to other market returns (i.e., column 4) were rejected for 7 cases, with the exception of Bitcoin-MSCI emerging markets and Bitcoin-US dollar.

With respect to the null hypothesis of equality in volatility-in-mean components in the bull and bear market conditions, the results in column 5 show that the null hypothesis was rejected at the $5 \%$ level in most cases and at the $10 \%$ level for Bitcoin-MSCI China in the case of the own riskreturn relation in Bitcoin markets, and for the Bitcoin-MSCI world dataset, the null hypothesis was rejected. Column 8 suggests that the null of equality in volatility-in-mean components in the bull and bear market conditions in the case of the own risk-returns relation for the other asset markets was rejected for the cases of Bitcoin-MSCI world, Bitcoin-MSCI emerging markets, Bitcoin-energy, and Bitcoin-US Treasury. In the other cases, the null hypothesis was rejected at a very high level of significance. Columns 6 and 7 report the results of the Wald tests of the null hypotheses of equality of the cross risk-return relation involving Bitcoin returns and other market returns across bull and bear regimes. The results suggested that the null hypothesis of equality of the effect of the risk from the Bitcoin market to other market returns in both bull and bear regimes could not be rejected in all cases, except for those of Bitcoin-Gold and Bitcoin-US Treasury. The similar null hypothesis in the case of the effect of risk from other market returns on Bitcoin market returns was rejected in all cases. Finally, Columns 10 and 11 show that the results of the tests of the two null hypotheses, 'no leverage effect' and 'no dynamic behavior' in the conditional correlation, respectively, suggest the rejection of both of these null hypotheses in all cases. 
Table 5. Results of the Wald test of equality of coefficients for bull and bear markets

\begin{tabular}{|c|c|c|c|c|c|c|c|c|c|c|c|}
\hline Column No. & 1 & 2 & 3 & 4 & 5 & 6 & 7 & 8 & 9 & 10 & 11 \\
\hline $\begin{array}{l}\text { Null } \\
\text { Hypothesis }\end{array}$ & $\begin{array}{l}b_{12}^{1}=b_{12}^{2} \\
=0\end{array}$ & $\begin{array}{l}b_{21}^{1}=b_{21}^{2} \\
=0\end{array}$ & $b_{12}^{1}=b_{12}^{2}$ & $b_{21}^{1}=b_{21}^{2}$ & $\lambda_{11}^{1}=\lambda_{11}^{2}$ & $\lambda_{13}^{1}=\lambda_{13}^{2}$ & $\lambda_{21}^{1}=\lambda_{21}^{2}$ & $\lambda_{23}^{1}=\lambda_{23}^{2}$ & $\lambda_{i j}^{1}=\lambda_{i j}^{2}$ & $\begin{array}{l}d_{1}=d_{2} \\
=0\end{array}$ & $\begin{array}{l}\varphi_{1}=\varphi_{2} \\
=0\end{array}$ \\
\hline $\begin{array}{l}\text { [Bitcoin, MSCI } \\
\text { world] }\end{array}$ & $\begin{array}{c}535.35^{*} \\
(0.00) \\
\end{array}$ & $\begin{array}{l}25.76^{*} \\
(0.00) \\
\end{array}$ & $\begin{array}{l}48.43^{*} \\
(0.00) \\
\end{array}$ & $\begin{array}{l}19.23^{*} \\
(0.00)\end{array}$ & $\begin{array}{c}2.61 \\
(0.10) \\
\end{array}$ & $\begin{array}{l}12.21^{*} \\
(0.00)\end{array}$ & $\begin{array}{c}0.75 \\
(0.38) \\
\end{array}$ & $\begin{array}{c}0.57 \\
(0.44) \\
\end{array}$ & $\begin{array}{c}543.44^{*} \\
(0.00) \\
\end{array}$ & $\begin{array}{c}145.68^{*} \\
(0.00) \\
\end{array}$ & $\begin{array}{c}2684.17^{*} \\
(0.00)\end{array}$ \\
\hline $\begin{array}{l}\text { [Bitcoin, MSCI } \\
\text { emerging markets] }\end{array}$ & $\begin{array}{l}127.62 * \\
(0.00)\end{array}$ & $\begin{array}{c}4.41 \\
(0.10) \\
\end{array}$ & $\begin{array}{l}15.89^{*} \\
(0.00) \\
\end{array}$ & $\begin{array}{c}2.50 \\
(0.11) \\
\end{array}$ & $\begin{array}{l}4.31 * * \\
(0.03) \\
\end{array}$ & $\begin{array}{l}6.27^{*} \\
(0.01) \\
\end{array}$ & $\begin{array}{c}0.80 \\
(0.37) \\
\end{array}$ & $\begin{array}{c}0.99 \\
(0.31) \\
\end{array}$ & $\begin{array}{l}127.61 * \\
(0.00)\end{array}$ & $\begin{array}{l}97.51^{*} \\
(0.00) \\
\end{array}$ & $\begin{array}{c}951.08^{*} \\
(0.00)\end{array}$ \\
\hline $\begin{array}{l}\text { [Bitcoin, MSCI } \\
\text { China] }\end{array}$ & $\begin{array}{l}107.70 * \\
(0.00)\end{array}$ & $\begin{array}{l}7.37 * * \\
(0.02)\end{array}$ & $\begin{array}{l}10.43^{*} \\
(0.00)\end{array}$ & $\begin{array}{l}5.33 * * \\
(0.02)\end{array}$ & $\begin{array}{c}3.38^{* * * *} \\
(0.06)\end{array}$ & $\begin{array}{l}7.03^{*} \\
(0.00)\end{array}$ & $\begin{array}{c}0.90 \\
(0.34)\end{array}$ & $\begin{array}{l}6.67^{*} \\
(0.00)\end{array}$ & $\begin{array}{c}158.99 * \\
(0.00)\end{array}$ & $\begin{array}{l}68.20^{*} \\
(0.00)\end{array}$ & $\begin{array}{l}991.59^{*} \\
(0.00)\end{array}$ \\
\hline $\begin{array}{l}\text { [Bitcoin, } \\
\text { commodity] }\end{array}$ & $\begin{array}{c}266.26^{*} \\
(0.00) \\
\end{array}$ & $\begin{array}{l}7.69^{* * *} \\
(0.02) \\
\end{array}$ & $\begin{array}{l}17.88^{*} \\
(0.00) \\
\end{array}$ & $\begin{array}{l}6.20^{*} \\
(0.01) \\
\end{array}$ & $\begin{array}{l}3.86^{* * *} \\
(0.04) \\
\end{array}$ & $\begin{array}{l}5.89^{*} \\
(0.01) \\
\end{array}$ & $\begin{array}{c}0.46 \\
(0.49) \\
\end{array}$ & $\begin{array}{l}65.99^{*} \\
(0.00) \\
\end{array}$ & $\begin{array}{c}224.15^{*} \\
(0.00) \\
\end{array}$ & $\begin{array}{c}116.36^{*} \\
(0.00)\end{array}$ & $\begin{array}{l}862.20^{*} \\
(0.00) \\
\end{array}$ \\
\hline [Bitcoin, energy] & $\begin{array}{l}52.65^{*} \\
(0.00)\end{array}$ & $\begin{array}{l}16.70^{*} \\
(0.00)\end{array}$ & $\begin{array}{l}12.40^{*} \\
(0.00)\end{array}$ & $\begin{array}{l}15.36^{*} \\
(0.00)\end{array}$ & $\begin{array}{l}6.40 * \\
(0.01)\end{array}$ & $\begin{array}{l}26.33 * \\
(0.00)\end{array}$ & $\begin{array}{c}0.14 \\
(0.70)\end{array}$ & $\begin{array}{c}0.01 \\
(0.90)\end{array}$ & $\begin{array}{c}199.07^{*} \\
(0.00)\end{array}$ & $\begin{array}{l}52.99 * \\
(0.00)\end{array}$ & $\begin{array}{c}996.46^{*} \\
(0.00)\end{array}$ \\
\hline [Bitcoin, Gold] & $\begin{array}{c}108.18^{*} \\
(0.00)\end{array}$ & $\begin{array}{c}3.61 \\
(0.16)\end{array}$ & $\begin{array}{l}34.75^{*} \\
(0.00)\end{array}$ & $\begin{array}{l}3.55^{* *} \\
(0.05)\end{array}$ & $\begin{array}{l}6.86^{*} \\
(0.00)\end{array}$ & $\begin{array}{l}22.59^{*} \\
(0.00)\end{array}$ & $\begin{array}{l}7.95^{*} \\
(0.00)\end{array}$ & $\begin{array}{l}14.34^{*} \\
(0.00)\end{array}$ & $\begin{array}{c}198.54 * \\
(0.00)\end{array}$ & $\begin{array}{l}35.71 * \\
(0.00)\end{array}$ & $\begin{array}{l}911.56^{*} \\
(0.00)\end{array}$ \\
\hline $\begin{array}{l}\text { [Bitcoin, US } \\
\text { dollar] }\end{array}$ & $\begin{array}{l}43.89^{*} \\
(0.00) \\
\end{array}$ & $\begin{array}{l}3.43^{*} \\
(0.00) \\
\end{array}$ & $\begin{array}{l}41.53^{*} \\
(0.00) \\
\end{array}$ & $\begin{array}{c}1.40 \\
(0.23) \\
\end{array}$ & $\begin{array}{l}13.76^{*} \\
(0.00) \\
\end{array}$ & $\begin{array}{c}150.39^{*} \\
(0.00) \\
\end{array}$ & $\begin{array}{c}1.72 \\
(0.18) \\
\end{array}$ & $\begin{array}{l}6.83^{*} \\
(0.00) \\
\end{array}$ & $\begin{array}{c}235.19^{*} \\
(0.00) \\
\end{array}$ & $\begin{array}{l}6.29 * * \\
(0.04) \\
\end{array}$ & $\begin{array}{l}599.43^{*} \\
(0.00) \\
\end{array}$ \\
\hline $\begin{array}{l}\text { [Bitcoin, US } \\
\text { Treasury] }\end{array}$ & $\begin{array}{l}98.40^{*} \\
(0.00)\end{array}$ & $\begin{array}{l}12.27 * \\
(0.00)\end{array}$ & $\begin{array}{l}20.32^{*} \\
(0.00)\end{array}$ & $\begin{array}{l}12.05^{*} \\
(0.00)\end{array}$ & $\begin{array}{l}8.04^{*} \\
(0.00)\end{array}$ & $\begin{array}{l}62.69^{*} \\
(0.00)\end{array}$ & $\begin{array}{l}11.10^{*} \\
(0.00)\end{array}$ & $\begin{array}{l}2.06 \\
(0.15)\end{array}$ & $\begin{array}{c}247.09^{*} \\
(0.00)\end{array}$ & $\begin{array}{l}57.24 * \\
(0.00)\end{array}$ & $\begin{array}{l}1378.05^{*} \\
(0.00)\end{array}$ \\
\hline
\end{tabular}

Note: $p$-values as above.

Our analyses above revealed evidence of significant return spillovers between Bitcoin and the four asset classes that often were asymmetric and differed depending on market conditions. These empirical findings contrast with those that claim that the Bitcoin market is isolated completely from the rest of the financial system (Ji et al., 2017) or is unaffected by economic and financial factors (Baek and Elbeck, 2015; Kristoufek, 2013; Ciaian et al., 2016). Our findings also were not consistent fully with prior observations that Bitcoin is not linked with UK equities and the US dollar (Dyhrberg, 2016) and thus has safe-haven properties. In fact, our results were consistent in part with those of $\mathrm{Li}$ and Wang (2017) who showed that Bitcoin's price is more sensitive to economic fundamentals than to technological factors. Our results also were somewhat consistent with those of Bouoiyour and Selmi (2015) and Kristoufek (2015), who stressed the close association between Bitcoin and the Chinese stock market. However, they differed with respect to the results involving gold. Unlike Bouoiyour and Selmi (2015) and Kristoufek (2015), we demonstrated a strong effect of gold on the Bitcoin market, probably attributable to the application of a different method and a longer sample period. With respect to the primary results of volatility spillovers, they revealed significant volatility spillovers to the Bitcoin market and almost no feedback effect. 


\section{Concluding remarks}

This study was motivated by the scarce evidence in the empirical literature on return and volatility spillovers between Bitcoin and several asset classes, and whether these spillovers exhibit nonlinearity and asymmetric effects that differ between bull and bear market conditions. Using a VAR-asymmetric GARCH model that captures the asymmetric nature of mean and volatility spillovers in two market conditions, and allowing a dynamic conditional correlation between pairs of assets, our analyses contribute to the related literature because of our application of a rich methodology, Bitcoin data, and extensive datasets of different asset classes. Our principal findings indicate that spillovers between Bitcoin and the assets classes studied are subject to time and market conditions, as seen previously for equity markets (Kundu and Sarkar, 2016). Bitcoin is connected with the other assets to a greater extent via return than volatility. There is an asymmetry in spillovers for Bitcoin and asset pairs where the recipient usually is Bitcoin. Specifically, the volatility in Bitcoin can be predicted based on that of the other assets, which is not the case in the converse situation.

As Bitcoin has shown signs of moderate integration with most of the asset classes studied, investors and fund managers must be cautious when combining Bitcoin with most of the asset classes, as several previous studies have shown (Baek and Elbeck, 2015; Baur et al., 2015; Brière et al., 2015; Bouri et al., 2017b; Ji et al., 2017). In doing so, market participants should account carefully for market conditions. Furthermore, they should not consider equities a homogenous asset class, but differentiate between world, emerging, and Chinese markets when making investment decisions involving Bitcoin. The same is true for commodities, energy, and gold. Furthermore, policymakers and regulators should be concerned about the return spillover effects from the Bitcoin market to that of equities. The fact that Bitcoin appears to receive from the different asset classes more than it takes suggests that Bitcoin does not present an imminent risk to the global financial system. However, it would be wise to continue to monitor the Bitcoin market (European Central Bank, 2012). This is very important if the exponential value appreciation in the Bitcoin market continues, which will make Bitcoin a larger player and potentially a source of instability for the global financial system.

Future research should consider the determinants of significant return and volatility spillovers between Bitcoin and these other assets. 


\section{References}

Baek, C., and Elbeck, M. (2015). Bitcoins as an investment or speculative vehicle? A first look. Applied Economics Letters, 22(1), 30-34.

Bai, J., and Perron, P. (2003). Computation and analysis of multiple structural change models. Journal of Applied Econometrics, 18(1), 1-22.

Baur, D., Lee, A., and Hong, K. 2015. Bitcoin: Currency or investment? Available at SSRN: https://ssrn.com/abstract=2561183.

Balcilar, M., Bouri, E., Gupta, R., and Roubaud, R. (2017). Can volume predict Bitcoin returns? A quantiles-based approach. Economic Modelling, 64, 74-81.

Bouoiyour, J., and Selmi, R. 2015. What does Bitcoin look like? Annals of Economics and Finance, 16(2), 449-492.

Bouri, E., Gupta, R., Tiwari, A. and Roubaud, D. (2017a). Does Bitcoin hedge global uncertainty? Evidence from wavelet-based quantile-in-quantile regressions. Finance Research Letters, 23, 87-95.

Bouri, E., Jalkh, N., Molnár, P., and Roubaud, D. (2017b). Bitcoin for energy commodities before and after the December 2013 crash: Diversifier, hedge or more? Applied Economics, 49(50), 5063-5073.

Brière, M., Oosterlinck, K., and Szafarz, A. (2015). Virtual currency, tangible return: Portfolio diversification with Bitcoins. Journal of Asset Management, 16(6), 365-373.

Broock, W. A., Scheinkman, J. A., Dechert, W. D., and LeBaron, B. (1996). A test for independence based on the correlation dimension. Econometric Reviews, 15(3), 197-235.

Chen, S. S. (2009). Predicting the bear stock market: Macroeconomic variables as leading indicators. Journal of Banking \& Finance, 33(2), 211-223.

Chowdhury, K. B., Kundu, S., and Sarkar, N. (2018). Regime-dependent effects of uncertainty on inflation and output growth: Evidence from the United Kingdom and the United States. Scottish Journal of Political Economy, dou: 10.1111/sjpe.12168.

Ciaian, P., Rajcaniova, M., and Kancs, D.A. (2016). The economics of Bitcoin price formation. Applied Economics, 48(19), 1799-1815. 
Dyhrberg, A. H. (2016). Hedging capabilities of Bitcoin. Is it the virtual gold? Finance Research Letters, 16, 139-144.

EBA. (2014). EBA Opinion on 'Virtual' Currencies. EBA/Op/2014/08, European Banking Authority.

Engle, R. F. (2002). Dynamic conditional correlation: A simple class of multivariate generalized autoregressive conditional heteroskedasticity models. Journal of Business \& Economic Statistics, 20(3), 339-350.

Engle, R. F., and Sheppard, K. (2001). Theoretical and empirical properties of dynamic conditional correlation multivariate GARCH (No. W8554). National Bureau of Economic Research.

European Central Bank (2012). Virtual Currency Schemes. October, 1-55.

Glosten, L. R., Jagannathan, R., and Runkle, D. E. (1993). On the relation between the expected value and the volatility of the nominal excess return on stocks. The Journal of Finance, 48 (5), 1779-1801.

Granger, C. W., and Terasvirta, T. (1993). Modelling non-linear economic relationships. OUP Catalogue.

Hayes, A. S. (2016). Cryptocurrency value formation: An empirical study leading to a cost of production model for Valuing Bitcoin. Telematics and Informatics,.

Ji, Q., Bouri, E., Gupta, R., and Roubaud, D. (2017). Network causality structures among Bitcoin and other financial assets: A directed acyclic graph approach. Department of Economics, University of Pretoria, Working Paper No. 201729.

Kristoufek, L. (2013). Bitcoin meets Google trends and Wikipedia: Quantifying the relationship between phenomena of the Internet era. Scientific Reports, 3, Article number 3415.

Kristoufek, L. (2015). What are the main drivers of the Bitcoin price? Evidence from wavelet coherence analysis. PloS One, 10(4), e0123923.

Kundu, S., and Sarkar, N. (2016). Return and volatility interdependences in up and down markets across developed and emerging countries. Research in International Business and Finance, 36, 297-311. 
Li, X., and Wang, C. A. (2017). The technology and economic determinants of cryptocurrency exchange rates: The case of Bitcoin. Decision Support Systems, 95, 49-60.

Mei, J., and Saunders, A. (1995). Bank risk and real estate: An asset pricing perspective. The Journal of Real Estate Finance and Economics, 10(3), 199-224.

Nelson, C. R. (1976). Inflation and rates of return on common stocks. The Journal of Finance, 31(2), 471-483.

Nelson, D. B. (1991). Conditional heteroskedasticity in asset returns: A new approach. Econometrica, 59, 347-370.

Polasik, M., Piotrowska, A. Wisniewski, T. P., Kotkowski, R., and Lightfoot, G. (2015). Price fluctuations and the use of Bitcoin: An empirical inquiry. International Journal of Electronic Commerce, 20(1), 9-49.

Rogojanu, A., and Badea, L. (2014). The issue of competing currencies. Case study-Bitcoin. Theoretical and Applied Economics, 21(1), 103-114.

Selgin, G. (2015). Synthetic commodity money. Journal of Financial Stability, 17, 92-99.

Terasvirta, T. (1994). Specification, estimation, and evaluation of smooth transition autoregressive models. Journal of the American Statistical Association, 89(425), 208218.

Tsay, R. S. (1989). Testing and modeling threshold autoregressive processes. Journal of the American Statistical Association, 84(405), 231-240.

Tse, Y. K., and Tsui, A. K. C. (2002). A multivariate generalized autoregressive conditional heteroscedasticity model with time-varying correlations. Journal of Business \& Economic Statistics, 20(3), 351-362.

Yelowitz, A., and Wilson, M. (2015). Characteristics of Bitcoin users: An analysis of Google search data. Applied Economics Letters, 22(13), 1030-1036.

Yermack, D. (2013). Is Bitcoin a real currency? An economic appraisal. (No. w19747). National Bureau of Economic Research. http://www.nber.org/papers/w19747. 


\section{Appendix}

\section{A.1 Preliminary analysis}

In this preliminary analysis, we focused on nonlinearity, multiple structural breaks, and model specification.

To assess the existence of nonlinearity, we applied Brock et al.'s (1996) BDS tests to the residuals of $\mathrm{AR}(1)$ models for the nine variables and the residuals from the Bitcoin equations of the VAR(1) model comprising the other variable one at a time. The $p$-values of the BDS test are reported in Table 1A. The results showed that, except for gold returns, the null hypothesis of no serial dependence was rejected at very high levels of significance. These results provide strong evidence of nonlinearity in not only the variables themselves, but also in their relation to Bitcoins.

\section{Table 1A. BDS independence test}

\begin{tabular}{|l|l|l|l|l|l|}
\hline & \multicolumn{5}{|c|}{ Dimensions } \\
\hline AR(1): Bitcoin & 2 & 3 & 4 & 5 & 6 \\
\hline AR(1): MSCI world & 0.00 & 0.00 & 0.00 & 0.00 & 0.00 \\
\hline AR(1): MSCI emerging markets & 0.00 & 0.00 & 0.00 & 0.00 & 0.00 \\
\hline AR(1): MSCI China & 0.00 & 0.00 & 0.00 & 0.00 & 0.00 \\
\hline AR(1): Commodity & 0.00 & 0.00 & 0.00 & 0.00 & 0.00 \\
\hline AR(1): Energy & 0.00 & 0.00 & 0.00 & 0.00 & 0.00 \\
\hline AR(1): Gold & 0.78 & 0.48 & 0.12 & 0.02 & 0.00 \\
\hline AR(1): US dollar & 0.02 & 0.00 & 0.00 & 0.00 & 0.00 \\
\hline AR(1): US Treasury Yield & 0.00 & 0.00 & 0.00 & 0.00 & 0.00 \\
\hline VAR(1): [Bitcoin, MSCI world] & 0.00 & 0.00 & 0.00 & 0.00 & 0.00 \\
\hline VAR(1): [Bitcoin, MSCI emerging markets] & 0.00 & 0.00 & 0.00 & 0.00 & 0.00 \\
\hline VAR(1): [Bitcoin, MSCI China] & 0.00 & 0.00 & 0.00 & 0.00 & 0.00 \\
\hline VAR(1): [Bitcoin, commodity] & 0.00 & 0.00 & 0.00 & 0.00 & 0.00 \\
\hline VAR(1): [Bitcoin, energy] & 0.00 & 0.00 & 0.00 & 0.00 & 0.00 \\
\hline VAR(1): [Bitcoin, Gold] & 0.00 & 0.00 & 0.00 & 0.00 & 0.00 \\
\hline VAR(1): [Bitcoin, US dollar] & 0.00 & 0.00 & 0.00 & 0.00 & 0.00 \\
\hline VAR(1): [Bitcoin, US Treasury] & 0.00 & 0.00 & 0.00 & 0.00 & 0.00 \\
\hline
\end{tabular}

Note: These are the $p$-values of the BDS test statistic, with the test applied to the residuals recovered from the AR(1) models of the nine variables and the residuals from the Bitcoin equations of the VAR(1) model comprising the other variables one at a time. 
We also carried out the Bai and Perron (2003) test of multiple structural breaks. As shown in Table 2A, there is evidence of structural breaks not only in the Bitcoin returns series, but also in their relations with other variables.

Table 2A. Bai-Perron (2003) tests for multiple breaks

\begin{tabular}{|l|l|}
\hline \multicolumn{2}{|c|}{ (Method: Global L breaks vs. none and Sequential L+1 breaks vs. L) } \\
\hline AR(1): Bitcoin & Break Dates \\
\hline AR(1): MSCI world & $11 / 19 / 2013$ \\
\hline AR(1): MSCI emerging markets & No break \\
\hline AR(1): MSCI China & No break \\
\hline AR(1): Commodity & No break \\
\hline AR(1): Energy & $6 / 23 / 2014$ and 1/21/2016 (WD max test) \\
\hline AR(1): Gold & $6 / 23 / 2014$ and 1/21/2016 (WD max test) \\
\hline AR(1): US dollar & No break \\
\hline AR(1): US Treasury Yield & No break \\
\hline VAR(1): [Bitcoin, MSCI world] & No break \\
\hline VAR(1): [Bitcoin, MSCI emerging markets] & $11 / 19 / 2013$ \\
\hline VAR(1): [Bitcoin, MSCI China] & $11 / 19 / 2013$ \\
\hline VAR(1): [Bitcoin, commodity] & $11 / 19 / 2013$ \\
\hline VAR(1): [Bitcoin, energy] & $11 / 19 / 2013$ \\
\hline VAR(1): [Bitcoin, Gold] & $11 / 19 / 2013$ \\
\hline VAR(1): [Bitcoin, US dollar] & $11 / 19 / 2013$ \\
\hline VAR(1): [Bitcoin, US Treasury] & $11 / 19 / 2013$ \\
\hline Nite: Brea Cos a based & $11 / 19 / 2013$ \\
\hline
\end{tabular}

Note: Break dates are based on the Bai and Perron (2003) test of multiple structural breaks applied to the AR(1) models of the nine variables and the Bitcoin equations of the VAR(1) model comprising the other variable one at a time.

We also conducted tests of linearity and model selection.

In the spirit of Tsay's (1989) seminal methodology, Camacho (2004) proposed a step-wise procedure to model the nonlinear VAR model with a smooth transition specification. In this context, one single-regime linear VAR model that is the case under the null is specified, and then the hypothesis of smoothness in the transition between regimes is tested. The null hypothesis of linearity is that the smooth transition parameter $\gamma$ is equal to zero, i.e., $H_{0}: \gamma=0$, and the alternative hypothesis is $H_{1}: \gamma>0$. Because the model is not identified under the null hypothesis, any statistical test that uses a regime switching model as the alternative suffers from a serious problem, the nuisance parameter problem. To avoid this issue, a standard Lagrange Multiplier (LM)-type test based on an auxiliary regression that is obtained from a suitable Taylor series expansion of the transition function around the point $\gamma=0$, was used (see Granger and 
Terasvirta, 1993 for details). Consistent with this proposal for the univariate case, Camacho (2004) proposed the following two auxiliary regressions for the bivariate case:

$$
\begin{aligned}
& r_{1 t}=\tau_{1}+\sum_{h=0}^{3} \xi_{1 h}^{\prime} X_{t} w^{h}+u_{1 t} \\
& \text { and } r_{2 t}=\tau_{2}+\sum_{h=0}^{3} \xi_{2 h}^{\prime} X_{t} w^{h}+u_{2 t}
\end{aligned}
$$

where $X_{t}^{\prime}=\left(r_{1 \overline{t-1}}, r_{2 \overline{t-1}}\right), \xi_{1 h}$ and $\xi_{2 h}$ are $(1 \times 2)$ coefficient vectors, and the variable $w$ is the transition variable, which is the lag value of returns. The null hypothesis of linearity thus corresponds to $\xi_{11}=\xi_{12}=\xi_{13}=\xi_{21}=\xi_{22}=\xi_{23}=0$.

If linearity, i.e., one single regime, is rejected in favor of additional regimes, the model selection test is then required to choose between logistic and exponential transition functions. To that end, a sequence of nested hypotheses was formulated for the two auxiliary regressions. Following Camacho (2004), the null and alternative hypotheses for the nested tests, together with the choice of an appropriate transition function, are presented in the following table. Three test statistics are involved in this exercise, and are denoted as Test 1, Test 2, and Test 3. Under the respective null hypothesis, these test statistics follow non-standard distributions, and their critical values are available in Camacho (2004).

\section{Table 3A. Model selection tests}

\begin{tabular}{|c|c|c|c|c|}
\hline Hypothesis & Test 1 & Test 2 & Test 3 & Choice \\
\hline Null & $\xi_{i 3}=0$ & $\xi_{i j}=0$, & $\xi_{i j}=0$, & $\ldots \ldots$ \\
& & $j=2,3$ & $j=1,2,3$ & \\
\hline Alternative & $\xi_{i 3} \neq 0$ & $\xi_{i 2} \neq 0$ & $\xi_{i 1} \neq 0$ & $\ldots \ldots$ \\
& & $\xi_{i 3}=0$ & $\xi_{i j}=0$ & \\
& & & $j=2,3$ & \\
\hline Test conclusion & Reject null & $\ldots \ldots$ & $\ldots \ldots \ldots$ & Logistic \\
& Do not reject null & Reject null & Do not reject null & Exponential \\
& Do not reject null & Do not reject null & Reject null & Logistic \\
& Do not reject null & Reject null & Reject null & No conclusion \\
\hline
\end{tabular}


As Table 4A shows, in all cases, the null hypothesis of linearity was rejected at very high levels of significance. Further, in most cases, the underlying nature of the smooth transition function is logistic.

Table 4A. Test of linearity and model selection

\begin{tabular}{|c|c|c|c|c|}
\hline & \multicolumn{4}{|c|}{ Transition variable } \\
\hline & \multicolumn{2}{|c|}{$r_{1, t-1}$} & \multicolumn{2}{|c|}{$r_{2, t-1}$} \\
\hline & Linearity test & Model selection & Linearity test & Model selection \\
\hline $\begin{array}{l}\text { [Bitcoin, MSCI } \\
\text { world] }\end{array}$ & $\begin{array}{l}68.86^{*} \\
(0.00)\end{array}$ & LSTVAR & $\begin{array}{l}67.79 * \\
(0.00)\end{array}$ & LSTVAR \\
\hline $\begin{array}{l}\text { [Bitcoin, MSCI } \\
\text { emerging markets] }\end{array}$ & $\begin{array}{l}38.72 * \\
(0.00)\end{array}$ & No Conclusion & $\begin{array}{l}56.72 * \\
(0.00)\end{array}$ & LSTVAR \\
\hline $\begin{array}{l}\text { [Bitcoin, MSCI } \\
\text { China] }\end{array}$ & $\begin{array}{l}33.69 * \\
(0.00)\end{array}$ & LSTVAR & $\begin{array}{l}63.63 * \\
(0.00)\end{array}$ & LSTVAR \\
\hline $\begin{array}{l}\text { [Bitcoin, } \\
\text { commodity] }\end{array}$ & $\begin{array}{l}46.86^{*} \\
(0.00)\end{array}$ & LSTVAR & $\begin{array}{l}66.18 * \\
(0.00)\end{array}$ & LSTVAR \\
\hline [Bitcoin, energy] & $\begin{array}{l}33.67 * \\
(0.00)\end{array}$ & LSTVAR & $\begin{array}{l}63.87 * \\
(0.00)\end{array}$ & LSTVAR \\
\hline [Bitcoin, Gold] & $\begin{array}{l}36.47^{*} \\
(0.00)\end{array}$ & No Conclusion & $\begin{array}{l}96.23 * \\
(0.00)\end{array}$ & LSTVAR \\
\hline [Bitcoin, US dollar] & $\begin{array}{l}17.88 * \\
(0.00)\end{array}$ & No Conclusion & $\begin{array}{l}66.24 * \\
(0.00)\end{array}$ & LSTVAR \\
\hline $\begin{array}{l}\text { [Bitcoin, US } \\
\text { Treasury] }\end{array}$ & $\begin{array}{l}34.60 * \\
(0.00)\end{array}$ & LSTVAR & $\begin{array}{l}58.32 * \\
(0.00)\end{array}$ & LSTVAR \\
\hline
\end{tabular}

Note: $p$-values as in text. 